\title{
Adipose-derived stem cells weigh in as novel therapeutics for acute lung injury
}

\author{
Kushagra Gupta', Anja Hergrueter' and Caroline A Owen 1,2,* \\ See related research by Zhang et al., http://stemcellres.com/content/4/1/13
}

\begin{abstract}
Acute lung injury is characterized by intense neutrophilic lung inflammation and increased alveolar-capillary barrier permeability leading to severe hypoxemia, and is associated with high mortality despite improvements in supportive care. There is an urgent need for effective therapies for acute lung injury. Zhang and colleagues tested the efficacy of adipose-derived stem cells in acute lung injury in mice. When adipose-derived stem cells were delivered to mice that had been challenged with lipopolysaccharide, they potently limited acute lung inflammation and injury in the mice, indicating that adipose-derived stem cells have therapeutic potential in acute lung injury in humans. Herein, we discuss the advantages and potential limitations of using adiposederived stem cells as therapeutics for human acute lung injury.
\end{abstract}

No effective pharmacologic therapies currently exist for acute lung injury (ALI) or its more severe form, the acute respiratory distress syndrome (ARDS). The only treatment positively affecting mortality in ARDS is low-tidal volume ventilation, but even when this is used mortality remains high, at approximately $40 \%$ [1]. Thus, there is an urgent need for effective therapies for ALI/ARDS. Mesenchymal stem cells (MSCs) are progenitor cells having self-renewal and multi-lineage differentiation capabilities along with anti-inflammatory and immuno-suppressive activities. MSCs have been shown to have efficacy in various models of acute and chronic inflammatory diseases [2] and are now emerging as promising cellbased therapeutics for ALI/ARDS.

*Correspondence: cowen@rics.bwh.harvard.edu

'Division of Pulmonary and Critical Care Medicine, Brigham and Women's Hospital and Harvard Medical School, Boston, MA 02115, USA

Full list of author information is available at the end of the article
MSCs include bone marrow-derived stem cells (BMSCs), MSCs in umbilical cord blood, and adipose-derived stem cells (ASCs). In the field of ALI/ARDS cell-based therapeutics, most attention has focused on BMSCs, which have therapeutic efficacy in rodent and human tissue models of ALI and sepsis [3,4]. However, a number of barriers that may limit the clinical usefulness of BMSCs in human ALI/ARDS have been identified $[5,6]$ (Table 1). Like BMSCs, ASCs have anti-inflammatory and immuno-suppressive activities. ASCs inhibit immune cell activation and proliferation by inducing cell-to-cell contact and signaling and releasing mediators that limit tissue injury [7]. ASCs have greater anti-inflammatory potential than BMSCs because they secrete higher levels of bioactive mediators [8]. This and other properties of ASCs (Table 1) make them an attractive alternative to BMSCs as cell-based therapeutics for human ALI/ARDS. Consistent with this concept, recent studies have shown that transplantation of autologous ASCs attenuates ischemia-reperfusion lung injury in rodents $[9,10]$.

The paper by Zhang and colleagues [11] builds upon this literature by examining whether ASCs have efficacy in a model of direct ALI in mice. Zhang and coworkers challenged mice with bacterial lipopolysaccharide (LPS) by oropharyngeal route, and $4 \mathrm{~h}$ later ASCs isolated from syngeneic mice (mASCs) or humans (hASCs) were delivered to the mice by the same route, and ALI severity was assessed 24 and $72 \mathrm{~h}$ later. The LPS-challenged and mASC- or hASC-treated mice lost less body weight, and had decreased alveolar-capillary barrier injury as assessed by broncho-alveolar lavage fluid albumin levels, and reduced alveolar septal thickening and exudates when compared with LPS-challenged mice not treated with ASCs. Treatment of the LPS-challenged mice with hASCs and mASCs also reduced polymorphonuclear neutrophil influx into the lungs, and suppressed lung levels of pro-inflammatory mediators. Murine ASCs increased lung levels of anti-inflammatory interleukin-10 in LPS-challenged mice.

A strength of the paper is its novel focus on ASCs as a therapy for ALI, and its approach to test ASCs therapeutically (rather than prophylactically) in an ALI model 
Table 1. Comparison of bone marrow-derived stem cells and adipose-derived stem cells as ALI/ARDS therapeutics

\begin{tabular}{lll}
\hline & ASCs & BMSCs \\
\hline Isolation of cells & $\begin{array}{l}\text { Safe, relatively non-invasive and inexpensive procedure. } \\
\text { Adipose tissue is abundant, expendable, easily accessible, } \\
\text { and can be a waste product of many therapeutic and } \\
\text { cosmetic procedures }\end{array}$ & Painful, invasive, and relatively costly procedure \\
Cell yields & High & Generally low \\
$\begin{array}{l}\text { Proliferation and } \\
\text { differentiation }\end{array}$ & $\begin{array}{l}\text { High proliferation kinetics; expandable in culture for } \\
\text { autologous transplantation }\end{array}$ & Differentiation ability impaired with increasing age \\
& Adipose tissue does not have high exposure to viruses & $\begin{array}{l}\text { Bone marrow cells are susceptible to virus infection } \\
\text { and replication, including hepatitis B and human } \\
\text { immunodeficiency virus }\end{array}$ \\
Efficacy & $\begin{array}{l}\text { Few reports of efficacy in lung injury models to date; not yet } \\
\text { tested in sepsis models }\end{array}$ & $\begin{array}{l}\text { Efficacy demonstrated in animal models of ALI and sepsis } \\
\text { Other }\end{array}$ \\
\hline
\end{tabular}

ALI, acute lung injury; ARDS, acute respiratory distress syndrome; ASC, adipose-derived stem cell; BMSC, bone marrow-derived stem cell.

that induces robust neutrophilic lung inflammation. Additionally, the authors compared the therapeutic efficacy of human versus murine ASCs. While both hASCs and mASCs attenuated ALI, it is noteworthy that for most ALI parameters examined, mASCs were more potent than hASCs. However, it is possible that hASCs have greater potency at restraining acute lung inflammation in human subjects.

The study of Zhang and colleagues has several limitations that need to be addressed before ASCs can be advanced to human clinical trials. First, no single ALI animal model can completely reproduce all the pathologic features of human ALI/ARDS. While the LPS model studied by Zhang and coworkers induces robust neutrophilic lung inflammation, it causes only modest alveolar-capillary barrier injury, which is a hallmark of ALI/ARDS. Thus, it will be important to test the efficacy of ASCs in ALI models associated with severe ALI (such as hyperoxia and acid-induced ALI) and to assess the effects of ASCs on physiologic readouts of ALI, including lung compliance and hypoxemia. Second, ALI/ARDS in humans is often initiated by bacterial infections, but the model chosen (LPS-mediated ALI) causes sterile lung inflammation. Given that ASCs suppress immune responses, it will be important to assess their effects on host responses to pathogens that can cause ALI/ARDS. Third, the mechanisms by which ASCs produce their beneficial effects in this model were not addressed. Fourth, given that ARDS patients are often not treated within the first 4 hours of illness (the single time-point when ASCs were delivered to mice in this study), future studies should determine how late in the disease course ASCs can be delivered and still induce a protective effect and for how long this protective effect is sustained. Moreover, the long-term safety of delivering ASCs was also not assessed in this study. It is noteworthy in this respect that hASCs promote the growth of tumor cells [12]. Therefore, before ASCs can be used to treat human subjects, it will be necessary to investigate their longterm safety in animals.

\section{Conclusion}

The study by Zhang and colleagues provides evidence that ASCs have potential as novel cell-based therapeutics for ALI/ARDS. The next logical step towards advancing ASCs into human clinical trials for ALI/ARDS will be to further test ASCs for their efficacy and safety in additional small and large animal models of ALI, including models more clinically relevant than the LPSmediated ALI model studied by Zhang and colleagues.

\section{Abbreviations}

ALI, acute lung injury; ARDS, acute respiratory distress syndrome; ASC, adipose-derived stem cell; BMSC, bone marrow-derived stem cell; hASC, human adipose-derived stem cell; LPS, lipopolysaccharide; mASC, mouse adipose-derived stem cell; MSC, mesenchymal stem cell;

\section{Competing interests}

$\mathrm{KG}, \mathrm{AH}$, and $\mathrm{CAO}$ have no financial or non-financial competing interests to declare in relation to this manuscript.

\section{Author's contributions}

$\mathrm{KG}, \mathrm{AH}$, and $\mathrm{CAO}$ all contributed to the writing of this manuscript.

\section{Author's information}

Kushagra Gupta, MD is a post-doctoral fellow, Anja Hergrueter is a research technician, and Caroline Owen, MD, PhD is an Assistant Professor of Medicine in the Division of Pulmonary and Critical Care Medicine at Brigham and Women's Hospital in Boston and Harvard Medical School. Dr Owen is also a fellow at the Lovelace Respiratory Research Institute, Albuquerque, NM.

\section{Acknowledgements}

This work was supported by PHS grants \#HL086814 and HL111835, and PO1HL105339, and The Brigham and Women's Hospital-Lovelace Respiratory Research Institute Consortium. These funding bodies had no role in the design or the writing of this manuscript or in the decision to submit the manuscript for publication. 


\section{Author details}

'Division of Pulmonary and Critical Care Medicine, Brigham and Women's Hospital and Harvard Medical School, Boston, MA 02115 USA. ${ }^{2}$ Fellow of the Lovelace Respiratory Research Institute, Albuquerque, NM 87108, USA.

Published: 28 February 2013

\section{References}

1. The Acute Respiratory Distress Syndrome Network: Ventilation with lower tidal volumes as compared with traditional tidal volumes for acute lung injury and the acute respiratory distress syndrome. NEng/ J Med 2000, 342:1301-1308.

2. Kaplan J M, Youd ME, Lodie TA: Immunomodulatory activity of mesenchymal stem cells. Curr Stem Cell Res Ther 2011, 6:297-316.

3. Gupta N, Su X, Popov B, Lee JW, Serikov V, and Matthay MA: Intrapulmonary delivery of bone marrow-derived mesenchymal stem cells improves survival and attenuates endotoxin-induced acute lung injury in mice. J Immunol 2007, 179:1855-1863.

4. Németh K, Leelahavanichkul A, Yuen PS, Mayer B, Parmelee A, Doi K, Robey PG, Leelahavanichkul K, Koller BH, Brown JM, Hu X, Jelinek I, Star RA, Mezey E: Bone marrow stromal cells attenuate sepsis via prostaglandin $\mathrm{E}(2)$ dependent reprogramming of host macrophages to increase their interleukin-10 production. Nat Med 2009, 15:42-49.

5. Yoo KH, Jang IK, Lee MW, Kim HE, Yang MS, Eom Y, Lee JE, Kim YJ, Yang SK, Jung HL, Sung KW, Kim CW, Koo HH: Comparison of immunomodulatory properties of mesenchymal stem cells derived from adult human tissues. Cell Immunol 2009, 259:150-156.

6. Ma R, Xing Q, Shao L, Wang D, Hao Q, Li X, Sai L, Ma L: Hepatitis B virus infection and replication in human bone marrow mesenchymal stem cells. Virol J 2011, 8:486.
7. Al BF, De KJ, Vanhaecke T, Rogiers V: Current status of human adiposederived stem cells: differentiation into hepatocyte-like cells. ScientificWorldJournal 2011, 11:1568-1581.

8. Banas A, Teratani T, Yamamoto Y, Tokuhara M, Takeshita F, Osaki M, Kawamata M, Kato T, Okochi H, Ochiya T: IFATS collection: in vivo therapeutic potential of human adipose tissue mesenchymal stem cells after transplantation into mice with liver injury. Stem Cells 2008, 26:2705-2712.

9. Sun CK, Yen CH, Lin YC, Tsai TH, Chang LT, Kao YH, Chua S, Fu M, Ko SF, Leu S, Yip HK: Autologous transplantation of adipose-derived mesenchymal stem cells markedly reduced acute ischemia-reperfusion lung injury in a rodent model. J Trans/ Med 2011, 9:118.

10. Yip HK, Chang YC, Wallace CG, Chang LT, Tsai TH, Chen YL, Chang HW, Leu S, Zhen YY, Tsai CY, Yeh KH, Sun CK, Yen CH: Melatonin treatment improves adipose-derived mesenchymal stem cell therapy for acute lung ischemiareperfusion injury. J Pineal Res 2013, 54:207-221.

11. Zhang S, Danchuk SD, Imhof KM, Semon JA, Scruggs BA, Bonvillain RW, Strong AL, Gimble JM, Betancourt AM, Sullivan DE, Bunnell BA: Comparison of the therapeutic effects of human and mouse adipose-derived stem cells in a murine model of lipopolysaccharide-induced acute lung injury. Stem Cell Res Ther 2013, 4:13.

12. Prantl L, Muehlberg F, Navone NM, Song YH, Vykoukal J, Logothetis CJ, Alt EU: Adipose tissue-derived stem cells promote prostate tumor growth. Prostate 2010, 70:1709-1715.

doi:10.1186/scrt167

Cite this article as: Gupta K, et al:: Adipose-derived stem cells weigh in as novel therapeutics for acute lung injury. Stem Cell Research \& Therapy 2013, 4:19. 